\title{
Lymphoepithelioma-Like Carcinoma of the Colon
}

\author{
Yasuharu Mori ${ }^{\mathrm{a}} \quad$ Kazunari Akagi ${ }^{\mathrm{a}} \quad$ Masaaki Yano $^{\mathrm{a}} \quad$ Hiroshi Sashiyama $^{\mathrm{a}}$ \\ Osamu Tsutsumi $^{a} \quad$ Yukihiro Hamahata $^{a}$ Yasunobu Tsujinaka ${ }^{a}$ \\ Akihiko Tsuchidab $^{\mathrm{b}}$ Jun Matsubayashi ${ }^{\mathrm{c}}$ \\ ${ }^{a}$ Department of Coloproctology, Tsujinaka Hospital Kashiwanoha, Chiba, and ${ }^{b}$ Division of \\ Gastroenterological Surgery and ${ }^{~}$ Department of Pathology, Tokyo Medical University \\ Hospital, Tokyo, Japan
}

\section{Key Words}

Lymphoepithelioma-like carcinoma - Lymphoid stroma · Adenocarcinoma · Colon cancer . Epstein-Barr virus

\begin{abstract}
A 70-year-old female underwent follow-up colonoscopy after colonic polypectomy. The colonoscopy revealed the presence of a 7-mm submucosal tumor in the sigmoid colon. The tumor surface was smooth and covered with normal mucosa. It was diagnosed as a submucosal tumor, and polypectomy was performed. Histopathological examination of the resected specimen revealed moderately to poorly differentiated adenocarcinoma measuring $2 \times 5 \times 3 \mathrm{~mm}$ with marked peritumoral lymphocytic infiltration and lymphoid follicle formation. It was diagnosed as carcinoma with lymphoid stroma (lymphoepithelioma-like carcinoma), SM $(1,800 \mu \mathrm{m})$, ly2, v0, budding; grade 1 . We confirmed the indication for noncurative additional surgical resection and performed laparoscopic sigmoid colectomy. No metastases were observed in the dissected lymph nodes.
\end{abstract}

\section{Introduction}

Lymphoepithelioma-like carcinoma (LELC) is histologically poorly differentiated and characterized by ill-defined borders, prominent stroma, intratumoral lymphoid infiltrate and a syncytial growth pattern. LELC has been reported in the nasopharynx, larynx, thymus, salivary grand, lung, vagina, tonsil, oval cavity, skin, urinary bladder and mammary gland. LELC occurring in the gastrointestinal tract is rare, and some reports are seen in the esophagus and stomach. The report is made as an Epstein-Barr virus (EBV)-related cancer by

Yasuharu Mori

Tsujinaka Hospital Kashiwanoha

148-6 Kashiwanoha Campus,178-2 Wakashiba, Kashiwa

277-0871 Chiba (Japan)

E-Mail yasmori_1@hotmail.com 
relation with EBV infection. Furthermore reports on colon involvement are very rare, only six reports having been seen in a past. The thing reported as EBV-related cancer is only one case, and the connection with EBV is unidentified in the colon. We experienced an example of LELC $5 \mathrm{~mm}$ in size that occurred in the sigmoid colon.

\section{Case Report}

Our case was 70-year-old female. She had neither diarrhea nor constipation. She had no obvious clinical signs and symptoms. Her family history was noncontributory. The patient visited our hospital for follow-up colonoscopy after colonic polypectomy. She had a past history of hyperlipidemia and glaucoma. Laboratory studies showed a carcinoembryonic antigen level of $0.7 \mathrm{IU} / \mathrm{ml}$ and a CA19-9 level of $6.0 \mathrm{ng} / \mathrm{ml}$. Colonoscopy revealed the presence of a 7-mm submucosal tumor in the sigmoid colon for which a snare polypectomy was performed. Melanosis of the deeper colon was observed. A 7-mm, white submucosal tumor that appeared to be expanding was present in the sigmoid colon; however, there was no central depression. The use of indigo carmine allowed clear visualization of the tumor margins and revealed no apparent differences between the tumor surface mucosa and the peritumoral mucosa; moreover, there were no abnormal structural features. The tumor was suggestive of lymphangioma of the colon; therefore a snare polypectomy was performed (fig. 1). Muscular layers were identified in the radial margins, and there were no findings suggestive of a residual tumor. The resected specimen was a submucosal tumor measuring $2 \times 5 \times 3 \mathrm{~mm}$, and an infiltrative growth suggestive of moderately to poorly differentiated adenocarcinoma was observed in the submucosa (fig. 2b). Lymphoid follicle formation with a germinal center was recognized in the circumference of the cancer cell nests (fig. 2a). The carcinoma mainly comprised infiltrating submucosal components. Mucinous components were also seen; therefore it was believed to be primary colorectal LELC. The tumor exhibited lymphatic invasion and was positive for Tub2, pSM $(1,800 \mu \mathrm{m})$, med, INFb, ly2, v0, HM0, VM0, and budding, and it was grade 1 with positive staining for D2-40 (fig. 3). Immunostaining was negative for CK7 and weakly positive for CK20, which is consistent with the characteristics of colorectal carcinomas.

Additional noncurative surgical resection was performed, and there were neither any residual tumors in the radial margins nor intra-lymph node metastases in the resected intestine. There has been no recurrence after operation for 1 year.

\section{Discussion}

Submucosal tumor of the colon is a rare presentation of colorectal carcinoma, and it is associated with three possible causes. Colorectal carcinoma in the form of a submucosal tumor first develops as surface-type early carcinoma and infiltrates the submucosa, where it grows rapidly by infiltrating the muscularis mucosae layer in an extremely early stage, even before horizontal growth. Lymphocytic infiltration is induced by a certain cytokine produced by the carcinoma cells during their growth process. Malignant and lymphocytic infiltration results in an increase in the amount of submucosal tissue, which in turn results in the presentation of submucosal tumor morphology. It is important to check whether central depression is present when examining submucosal tumor-like lesions because this is one of the features of colorectal carcinoma. No central depression, signs of infiltration, or redness were observed on the mucosal surface of the tumor in the present case. 
The correlation between EBV infection and LELC of the larynx, stomach and lungs has been thoroughly demonstrated. LELC reportedly occurs at various sites, including the esophagus, stomach, salivary glands, lungs, thymus, skin, uterine cervix, tongue, oral cavity, trachea, pharynx, bladder and vagina. Of these, the stomach is the most frequently reported digestive organ to be affected. These tumors have been described as EBV-associated carcinomas. EBV-associated carcinomas in organs other than the stomach have also been revealed by immunohistochemistry in several studies. LELC is thought to be associated with EBV. In the stomach, 85-92\% of LELC cases have been positive for EBER [1]. To compare the prevalence of EBV infection between LELC and non-LELC adenocarcinoma, the cases with LELC and gastric carcinoma with lymphoid stroma were extracted from the publication. EBV was detected in $152(86.4 \%)$ of the 176 LELC cases and in 224 (6.1\%)of the 3,649 non-LELC cases. The prevalence of EBV involvement in LELC was significantly higher than that of the non-LELC cases. Meta-analysis confirmed that EBVaGC is significantly associated with gastric LELC. Consistent with previous studies, the overall Odds ratio of EBV involvement in gastric LELC was 80.9 [2].

To our knowledge, only 7 cases, including the present (4 males, 3 females; are range 2585 years, mean age 62.1 years), of LELC occurring in the colon have been reported (table 1) [3-8]. The sites of involvement in these cases were widely distributed from the ascending colon to the rectum. However, endoscopic resection was only performed in the present case. Concerning the histological type of LELC, poorly differentiated adenocarcinoma was the most frequent. However LELC is known to be relative less aggressive clinically despite its poorly differentiated features [9]. Immunohistochemistry revealed EBV-positive tumor cells in only one case that presented with two tumors and ulcerative colitis in the background mucosa. The patient underwent partial colectomy, but the tumor recurred. Eventually, total colectomy was performed.

The case had other colorectal carcinoma, which had been well-differentiated adenocarcinoma and positive for p53 immunoreaction. However, the lesion described here was poorly differentiated and negative for p53. In the background nonneoplastic epithelial region, dysplasia with a hyperplastic lymphoid stroma was also seen, indicating that the present case was not a typical ulcerative colitis-related carcinoma. Other molecular pathways, such as EBV participation, resemble LELC carcinogenesis of other organs. EBV infection may be involved in carcinogenesis in cases with a background of ulcerative colitis by behaving as a stimulating factor for neoplasia in preneoplastic cells [7].

EBV-encoded small RNAs in situ hybridization for EBV was conducted for tumor cells and peripheral lymphocytes from the present case in order to examine their association with EBV; the results were negative (fig. 4). The association between EBV and LELC needs to be examined in detail, and it is necessary to clarify in future studies whether EBV infection is involved in carcinogenesis. 


\begin{tabular}{l|l}
\hline Case Rep Gastroenterol 2013;7:127-133 \\
\hline DOI: $\underline{10.1159 / 000348765}$ & $\begin{array}{l}\text { C 2013 S. Karger AG, Basel } \\
\text { www.karger.com/crg }\end{array}$ \\
\hline
\end{tabular}

Mori et al.: Lymphoepithelioma-Like Carcinoma of the Colon

\section{References}

1 Chang MS, Kim WH, Kim CW, Kim YI: Epstein-Barr virus in gastric carcinomas with lymphoid stroma. Histopathology 2000;37:309-315.

-2 Lee JH, Kim SH, Han SH, An JS, Lee ES, Kim YS: Clinicopathological and molecular characteristics of EpsteinBarr virus-associated gastric carcinoma: a meta-analysis. J Gastroenterol Hepatol 2009;24:354-365.

-3 Vilor M, Tsutsumi Y: Localization of Epstein-Barr virus genome in lymphoid cells in poorly differentiated adenocarcinoma with lymphoid stroma of the colon. Pathol Int 1995;45:695-697.

4 Samaha S, Tawfik O, Horvat R, Bhatia P: Lymphoepithelioma-like carcinoma of the colon: report of a case with histologic, immunohistochemical, and molecular studies for Epstein-Barr virus. Dis Colon Rectum 1998;41:925-928.

-5 De Petris G, Lev R, Quirk DM, Ferbend PR, Butmarc JR, Elenitoba-Johnson K: Lymphoepithelioma-like carcinoma of the colon in a patient with hereditary nonpolyposis colorectal cancer. Arch Pathol Lab Med 1999;123:720-724.

6 Kon S, Kasai K, Tsuzuki N, Nishibe M, Kitagawa T, Nishibe T, Sato N: Lymphoepithelioma-like carcinoma of rectum: possible relation with EBV. Pathol Res Pract 2001;197:577-582.

-7 Kojima Y, Mogaki M, Takagawa R, Ota I, Sugita M, Natori S, Hamaguchi Y, Kurosawa H, Fukushima T, Masui H, Fukazawa S, Yamanaka S, Tsuura Y, Nagahori K: A case of lymphoepithelioma-like carcinoma of the colon with ulcerative colitis. J Gastroenterol 2007;42:181-185.

8 Delaney D, Chetty R: Lymphoepithelioma-like carcinoma of the colon. Int J Clin Exp Pathol 2012;5:105-109.

-9 Nacopoulou L, Azaris P, Papacharalampous N, Davaris P: Prognostic significance of histologic host response in cancer of the large bowel. Cancer 1981;47:930-936.

Table 1. Reported cases of LELC of the colon

\begin{tabular}{|c|c|c|c|c|c|c|c|c|c|c|}
\hline $\begin{array}{l}\text { Reference } \\
\text { (first author) }\end{array}$ & $\begin{array}{l}\text { Age, } \\
\text { years }\end{array}$ & Sex & Location & Size, mm & Pathology & $\begin{array}{l}\text { ISH } \\
\text { (EBV) }\end{array}$ & $\mathrm{T}$ & $\mathrm{N}$ & ly & $\mathrm{v}$ \\
\hline Vilor, 1995 [3] & 77 & 우 & $\mathrm{T} / \mathrm{C}$ & 120 & por & negative & SS & - & - & - \\
\hline Samaha, 1998 [4] & 62 & $\sigma^{7}$ & $\mathrm{Ce}$ & $28 \times 27 \times 5$ & tub2 & negative & SS & 1 & & \\
\hline De Petris, 1999 [5] & 44 & $\sigma^{7}$ & $\mathrm{~A} / \mathrm{C}$ & 9 & tub1 & negative & & & & \\
\hline Kon, 2001 [6] & 72 & $\sigma^{7}$ & $\mathrm{R}$ & $20 \times 25 \times 7$ & por & positive & MP & 0 & 1 & 0 \\
\hline Kojima, 2007 [7] & 25 & $\sigma^{7}$ & $\mathrm{~S} / \mathrm{C}$ & 7 & por & negative & $\mathrm{SM}$ & 0 & & \\
\hline Delaney, 2012 [8] & 85 & 우 & $\mathrm{S} / \mathrm{C}$ & $42 \times 30 \times 15$ & por & negative & MP & 0 & 0 & 0 \\
\hline Our case, 2012 & 70 & 우 & $\mathrm{S} / \mathrm{C}$ & $2 \times 5 \times 3$ & tub2 por & negative & SM & 0 & 2 & 0 \\
\hline
\end{tabular}

ISH = In situ hybridization. 


\section{Case Reports in \\ Gastroenterology}

\begin{tabular}{l|l}
\hline Case Rep Gastroenterol 2013;7:127-133 \\
\hline DOI: $\underline{10.1159 / 000348765}$ & $\begin{array}{l}\text { ○ 2013 S. Karger AG, Basel } \\
\text { www.karger.com/crg }\end{array}$ \\
\hline
\end{tabular}

Mori et al.: Lymphoepithelioma-Like Carcinoma of the Colon

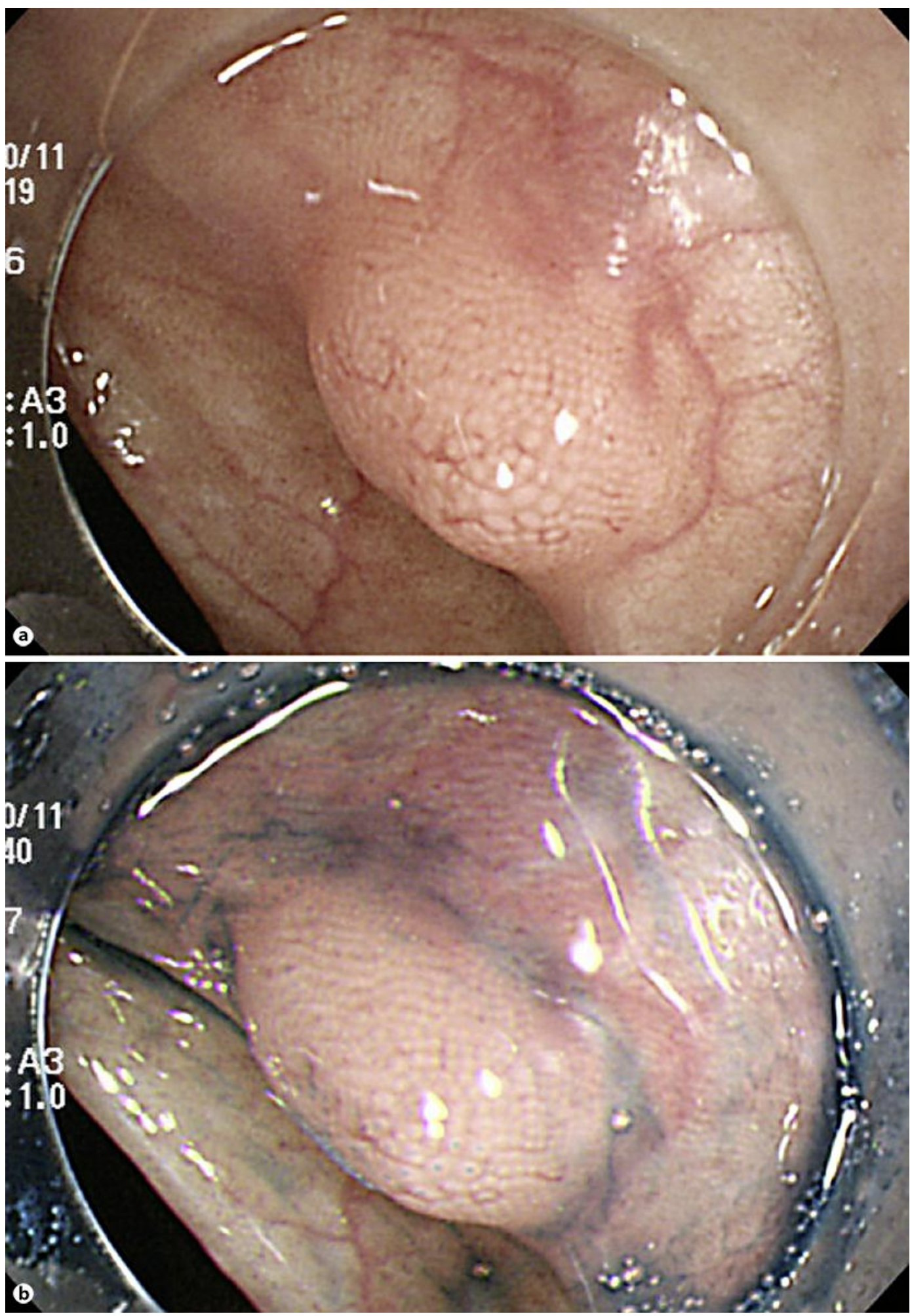

Fig. 1. Colonoscopy findings. a An elevated submucosal tumor is observed in the sigmoid colon. b After indigo carmine irrigation. There is no central depression on the tumor surface, which is covered with normal mucosa. 

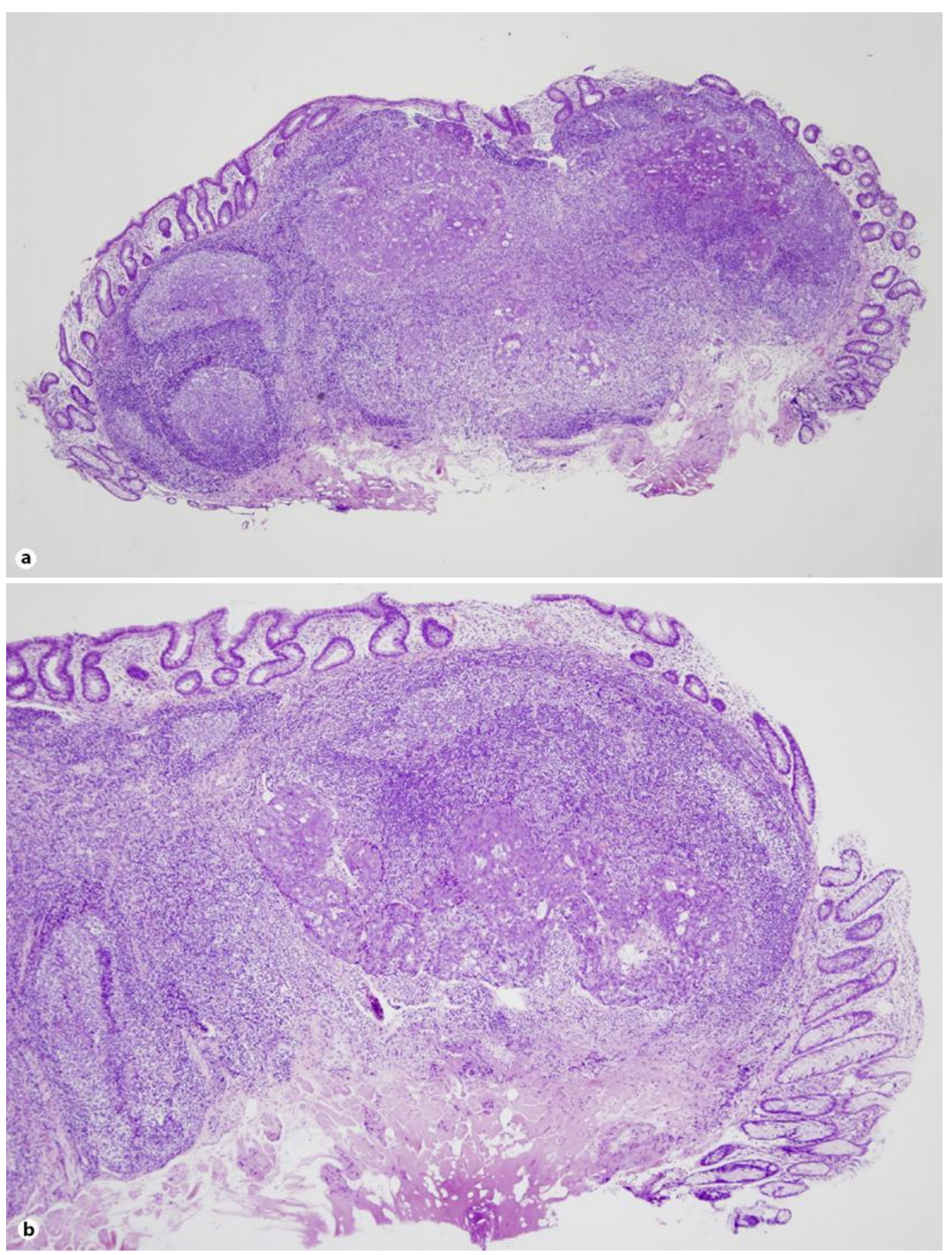

Fig. 2. Microscopic examination. a Lymphoid follicle formation is observed in the cancer cell nest circumference (HE, loupe). b An infiltrative growth suggestive of moderately to poorly differentiated adenocarcinoma is observed in the submucosa (HE, $\times 4)$. 


\begin{tabular}{|c|c|c|}
\hline \multirow{2}{*}{$\begin{array}{l}\text { Case Reports in } \\
\text { Gastroenterology }\end{array}$} & \multicolumn{2}{|c|}{ Case Rep Gastroenterol 2013;7:127-133 } \\
\hline & DOI: $\underline{10.1159 / 000348765}$ & $\begin{array}{l}\text { (c) } 2013 \text { S. Karger AG, Basel } \\
\text { www.karger.com/crg }\end{array}$ \\
\hline
\end{tabular}

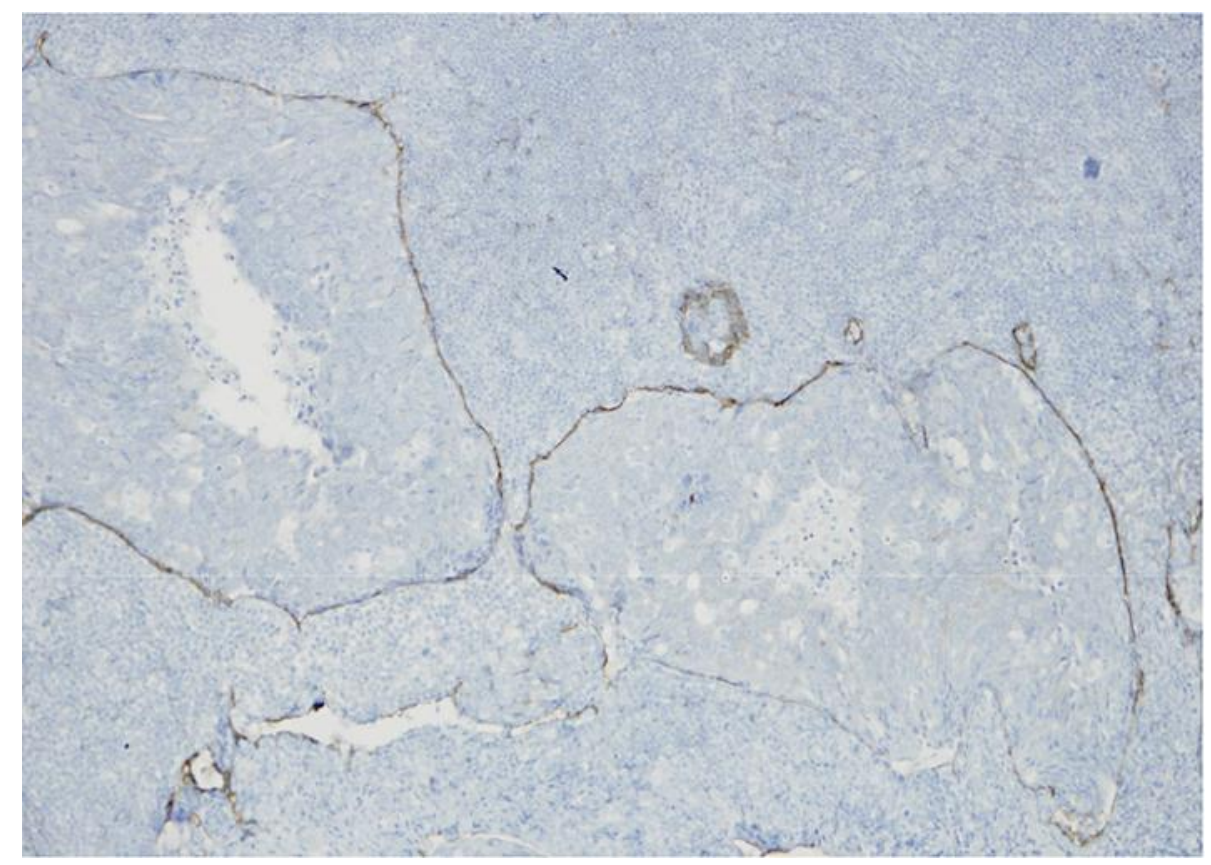

Fig. 3. D2-40 staining reveals a cancer cell nest in the lymphatic vessel $(\times 20)$.

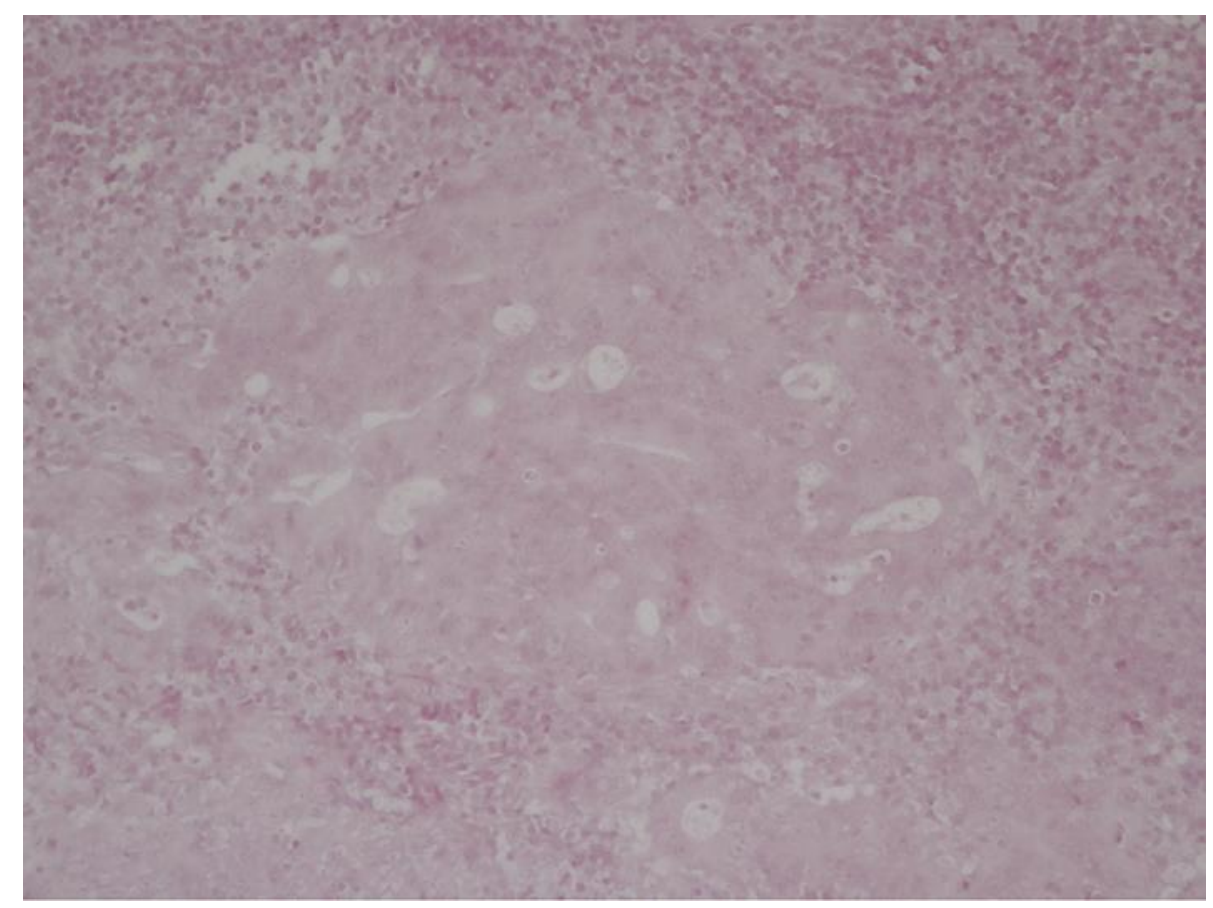

Fig. 4. EBV was not detected by in situ hybridization in the tumor cell, but was found in surrounding lymphocytes and nuclear $(\times 20)$. 